\title{
ANALISIS EFEKTIVITAS PENGENDALIAN INTERN PERSEDIAAN BARANG DAGANGAN PADA PT. KIMIA FARMA APOTEK 74 MANADO
}

\author{
Sitti Amanah Tontoli ${ }^{1}$, Inggriani Elim ${ }^{2}$, Victorina Z. Tirayoh ${ }^{3}$ \\ 1,2,3 Jurusan Akuntansi, Fakultas Ekonomi dan Bisnis, Universitas Sam Ratulangi, Jl. Kampus Bahu, Manado, \\ 95115, Indonesia \\ E-mail : Cittytontoli@gmail.com
}

\begin{abstract}
At a trading company, inventory is an important resource for the survival of the company because in addition to an asset whose value is greater than other current assets is also due to the main source of revenue comes from the sale of inventory. Therefore, effective internal controls are needed to manage the inventory to avoid errors and irregularities. The company is engaged in the pharmaceutical retail sector to manage existing company pharmacies in an effort to increase sales contribution, so that management of inventory management becomes important. The purpose of this study is to determine whether the internal control of merchandise inventory has been effective. The object of this research is PT. Kimia Farma 74 Manado. This research uses descriptive qualitative The results showed that the internal control of inventory at PT. Kimia Farma Apotek has been effective in applying pharmacy management management, which can be seen in the implementation of the elements of adequate internal control, good control of the inventory. However, there are still weaknesses in the form of duplicate duties on the function of receipt and storage of merchandise inventory and cash, as well as internal auditor functions captured by the accounting and finance.
\end{abstract}

\section{PENDAHULUAN}

Secara umum, perusahaan dagang dapat didefinisikn sebagai organisasi yang melakukan kegiatan usaha dengan membeli barang dari pihak atau perusahaan lain kemudian menjualnya kembali kepada masyarakat, karena di samping merupakan aset yang nilainya paling besar dibanding aktiva lancar lainnya dalam neraca perusahaan, juga disebabkan sumber utama pendapatan perusahaan dagang umumnya terdiri dari beraneka ragam jenis barang dagang dengan jumlah yang relatif banyak, sehingga rentan terhadap berbagai kerusakan, keusangan, kelebihan maupun kekurangan persediaan, maka perusahaan harus mempunyai suatu sistem pengelolaan persediaan yang efektif.

Pengendalian internal atas persedian barang dagangan diharapkan dapat menciptakan aktivitas pengendalian yang efektif dalam menentukan jumlah persediaan optimal yang dimiliki perusahaan, mencegah berbagai tindakan pelanggaran dan penyelewengan yang dapat merugikan perusahaan, penyalanggaran terhadap kebijakan yang ditetapkan atas persediaan, serta memberikan pengamanan fisik terhadap persediaan dari pencurian dan kerusakan. Penerapan dan pelaksanaan pengendalian internal juga menjadi hal yang penting dalam menentukan potensi kesalahan dan ketidakberesan serta dampak yang akan terjadi pada laporan keuangan, misalnya mengenai reabilitas dan akurasi penyajian laporan keuangan. Dengan adanya pengendalian internal yang baik dan teratur dalam mengelola persediaan barang dagangan, maka pemimpin perusahaan akan memperoleh informasi berupa laporan-laporan yang bermanfaat untuk meningkatkan efektifitas perusahaan, juga membantu dalam mengambil kebijakan keputusan maupun pertanggungjawaban dalam memimpin perusahaan.

Salah satu apotek yang berskala nasional adalah PT. Kimia Farma Apotek. Perusahaan ini adalah anak perusahaan yang dibentuk oleh Kimia Farma yang bergerak 
disektor ritel farmasi untuk mengola apotek-apotek milik perusahaan yang ada, dalam upaya meningkatkan kontribusi penjualan untuk memperbesar penjualan konsolidasi PT. Kimia Farma Tbk. Dalam hal tersebut, persediaan yang menjadi sumber utama pendapatan perusahaan ini melalui proses penjualan persediaannya yang berbentuk barang dagangan tentu saja mempunyai pengendalian internal atas persediaan barang dagangannya tersebut, dimana sewaktu-waktu dapat muncul masalah didalamnya sehingga dapat mengurangi keefektivitasan pengelolaan persediaan dan berpengaruh terhadap nilai informasi penyajian laporan keuangan.

Berdasarkan uraian-uraian yang ada mengenai pentingnya pengendalian internal persedian barang dagangan, maka penulis tertarik untuk meneliti hal tersebut, khususnya pada PT. Kimia Farma Apotek 74 yang beralamat di J1. Samrat No. 31 Kota Manado Provinsi Sulawesi Utara dengan judul"Analisis Efektivitas Pengendalian Intern Persediaan Barang Dagangan pada PT. Kimia Farma Apotek 74 Manado".

\section{TINJAUAN PUSTAKA}

\subsection{Konsep Pengendalian Internal Menurut COSO}

Pengendalian internal menurut COSO (Committee of Sponsoring Organization) yaitu:

1. Lingungan Pengendalian, komponen ini meliputi sikap manajemen disemua tingkatan terhadap operasi secara umum dan konsep pengendalian secara khusus

2. Penilaian risiko merupakan hal yang paling penting bagi manajemen. Penentuan risiko mencakup penentuan risiko disemua aspek organisasi dan penentuan kekuatan organisasi melalui evaluasi risiko.

3. Aktivitas pengendalian, Aktivitas ini meliputi persetujuan, tanggung jawab dan kewenangan, pemisahan tugas rekonsiliasi, karyawan kompeten dan jujur, pemeriksaan internal dan audit internal.

4. Informasi dan Komunikasi, komunikasi informasi tentang operasi pengendalian internal memberikan substansi yang dapaat digunakan manajemen untuk mengevaluasi efektivitas pengendalian dan untuk mengelola operasinya.

5. Pengawasan dan Pemantauan, pengawasan merupakan evaluasi rasional yang dinamis atas informasi yang diberikan pada komunikasi informasi untuk tujuan manajemen pengendalian, pemantauan adalah proses yang menentukan kualitas kinerja pengendalian internal sepanjang waktu.

\subsection{Tujuan Pengendalian Internal}

Pengendalian intern Menurut Mulyadi (2010:163) adalah sebagai berikut.

1. Menjaga kekayaan organisasi.

Kekayaan fisik suatu perusahaan dapat dicuri, disalahgunakan atau hancur karena kecelakaan kecuali jika kekayaan tersebut dilindungi dengan pengendalian yang memadai. Begitu juga dengan kekayaan perusahaan yang tidak memiliki wujud fisik seperti piutang dagang akan rawan oleh kekurangan jika dokumen penting dan catatan tidak dijaga.

2. Mengecek ketelitian dan keandalan data akuntansi.

Manajemen memerlusankan informasi keuangan yang diteliti dan andal untuk menjalankan kegiatan usahanya. Banyak informasi akuntansi yang digunakan oleh manajemen untuk dasar pengambilan keputusan penting. Pengendalian internal dirancang untuk memberikan jaminan proses pengolahan data akuntansi mencerminkan perubahan kekayaan perusahaan.

3. Mendorong efesiensi 
Pengendalian internal ditunjukan untuk mencegah dipublikasi usaha yang tidak perlu atau pemborosan dalam segala kegiatan bisnis perusahaan dan untuk mencegah penggunaan sumber daya perusahaan yang tidak efisien.

4. Mendorong dipatuhinya kebijakan manajemen.

\subsection{Pengendalian Internal atas Persediaan}

Menurut Hery (2009), pengengendalian internal atas persediaan seharusnya dimulai pada saat barang diterima (yang di beli pemasok). Laporan penerimaan barang yang bernomor urut tercetak, seharusnya disiapkan oleh bagian penerimaan untuk menetapkan tanggung jawab awalm atas persediaan. Untuk memastikan bahwa barang yang diterima sudah sesuai dengan apa yang dipesan, setiap laporan penerimaan barang harus dicocokkan dengan formulir pesanan pembelian yang asli. Pengendalian internal atas persediaan juga seringkali melibatkan bantuan alat pengaman, seperti kaca dua arah, kamera, sensor mengetik, kartu akses gudang, pengatur suhu ruangan, petugas keamanan dan sebagainya.

\subsection{Tujuan Pengendalian Internal atas Persediaan}

Tujuan pengendalian internal persediaan barang dagangan adalah sebagai berikut.

1. Transaksi benar-benar terjadi dan dilaksanakan (eksistensi); menyatakan bahwa transaksi yang dicatat adalah transaksi yang benar-benar terjadi dalam perusahaan.

2. Transaksi yang terjadi didefinisikan dan dicatat secara lengkap (kelengkapan); menyatakan bahwa transaksi telah dicatat dengan lengkap sehingga mencegah penghilagan transaksi dari catatan.

3. Transaksi yang terjadi telah dicatat dengan benar (akurasi); menyatakan bahwa transaksi telah dicatat dengan benar. Tujuan ini menyangkut keakuratan informasi untuk transaksi telah dicatat dengan benar. Tujuan ini menyangkut keakuratan informasi untuk transaksi akuntansi.

4. Transaksi yang terjadi diklasifikasikan dengan benar (klasifikasi) menyatakan bahwa transaksi yang telah terjadi diklasifikasikan pada perkiraan yang benar.

5. Transaksi yang terjadi dicatat pada saat yang tepat (ketepatan waktu); menyatakan bahwa transaksi yang dicatat pada waktu yang tepat,sehingga laporan keuangan yang dihasilkan benar-benar dapat bermanfaat.

\subsection{Penelitian Terdahulu}

1. Penelitian yang dilakukan Aprilia (2014) hasil penelitianya menunjukkan CV. Multi Media Persada Manado atas pengendalian intern sudah baik, karena telah menerapkan unsur-unsur pengendalian intern. Disarankan pihak manajemen dapatmelakukan pencatatan manual serta menyediakan staf ahli dalam menilai kualitas barang dagangan.

2. Penelitian yang dilakukan Cyntia (2015) hasil penelitiannya menunjukkanPengendalian internal atas persediaan pada Grand Hardware sudah efektif, dimana adanya pemisahan diantara fungsi-fungsi terkait dengan penerimaan dan pengeluaran barang. Pemantauan terhadap persediaan barang dagangan juga dilakukan secara periodik oleh bagian logistik melalui kegiatan stok opname. Pimpinan Grand Hardware sebaiknya mengimplementasikan pengendalian internal secara terstruktur serta membuat auditor internal tersendiri, agar pengendaliannya menjadi lebih efektif 


\section{METODE PENELITIAN}

\subsection{Jenis dan Sumber Data}

Jenis data yang digunakan adalah data Kualitatif adalah data yang berhubungan dengan kategorisasi, karakteristik berwujud pernyataan atau berupa kata-kata. Data ini biasanya didapat dari wawancara yang bersifat subjektif.Sumber data Data Sekunder adalah data yang diperoleh secara tidak langsung melalui media perantara (Melihat penelitian yang sudah pernah dilakukan sebelumnya), menggunakan metode tinjauan kepustakaan (library reserch) membaca buku-buku yang berkaitan dengan masalah yang ingin diteliti, dan dilihat dari mengakses website dan situs-situs yang di berkaitan.

\subsection{Metode Analisis Data}

Metode analisis yang digunakan dalam penelitian ini adalah metode deskriptif. Sugiyono (2009:206) analisis deskriptif adalah statistik yang digunakan untuk menganalisa data dengan cara mendeskripsikan atau menggambarkan data yang telah terkumpul sebagaimana adanya tanpa bermaksud membuat kesimpulan yang berlaku untuk umum atau generalisasi.

\section{HASIL ANALISIS DAN PEMBAHASAN}

\subsection{Hasil Penelitian}

1. Lingkungan pengendalian

a. Falsafah Manajemen dan Gaya Operasi

PT. Kimia Farma memiliki falsafah dalam organisasi dan nilai-nilai panutan guna mencapai sasaran yang dituju. Falsafah perusahaan mengandung aturan-aturan dimana setiap insannya menjalankan falsafah tersebut dalam setiap kegiatan bisnisnya. Falsafah dari PT. Kimia Farma adalah sebagai berikut.

b. Struktur Organisasi

Struktur organisasi yang dianut oleh PT. Kimia Farma Apotek berbentuk lini. Organisasi lini adalah bentuk organisasi dimana hubungan atasan dan bawahan dilakukan secara langsung. Dengan demikian pegawai bertanggung jawab kepada atasan sesuai dengan jenjang kepemimpinan dan hanya mengenal satu atasan sebagai sumber kewenangan dalam memberikan perintah atau instruksi.

c. Komite Audit

Komite audit PT. Kimia Farma Apotek berada langsung dibawah dewan komisaris dan berkedudukan dikantor pusat, yang padasaat-saat tertentu atau minimal dua kali dalam setahun mengadakan pemeriksaan terhadap jalannya operasional dan tujuan-tujuan yang ditetapkan sebelumnya oleh manajemen pusat dan cabang.

d. Penetapan Wewenang dan Tanggung Jawab

Penetapan wewenang dan tanggung jawab pada PT. Kimia Farma Apotek dirumuskan dan dideskripsikan secara tertulis dalam uraian tugas perusahaan.

e. Metode Pengendalian Manajemen

Untuk tujuan pengendalian persediaan barang dagangan, PT. Kimia Farma Apotek menggunakan metode pengendalian manajemen dengan teknik pertimbangan manajemen, dimana pengadaan barang dagangan disesuaikan dengan permintaan dari outlet-outlet dan berdasarkan rata-rata penjualan atau Pareto.

2. Penilaian Resiko

Dalam Proses penaksiran resiko yang mungkin timbul dalam perusahaan, PT. Kimia Farma mempertimbangkan faktor-faktor yang mungkin timbul.

3. Informasi dan Komunikasi 
Informasi dan Komunikasi yang ada pada PT. Kimia Farma Apotek berjalan dengan lancer. Informasi yang diperlukan untuk pimpinan disajikan oleh pihak yang berkepentingan untuk mengindentifikasikan tindakan yang akan dilakukan.

4. Aktivitas Pengendalian

Aktivitas pengendalian pada PT. Kimia Farma Apotek meliputi adanya kebijakan dan prosedur-prosedur yang dijalankan dalam perusahaan yang dapat menjamin bahwa sistem tersebut telah berjalan dengan efektif.

5. Pemantauan

Proses pemantauan biasanya dilakukan oleh manajer bisnis apotek dibantu oleh bagian internal auditor dari kantor pusat melalui pemantauan langsung dan pemeriksaan atas aktivitas yang akan terjadi, dimana keduanya melakukan penilaian secara terpisah, kemudian mendiskusikan dan mengadakan perbaikan yang dilakukan.

\subsection{Pembahasan}

1. Lingkungan Pengendalian

a. Falsafah Manajemen dan Gaya Operasi

PT. Kimia FarmaApotekmemilikifalsafahdalammenjalankansetiapkegiatanbisnisnya, meliputiprofessional,Enterpeneurship, dan care, yang menjadi

parameterbagiperusahaandankaryawan.

b. Struktur Organisasi

Struktur organisasi yang dirancang dan disusun PT. Kimia Farma Apotek telah memenuhi bentuk struktur organisasi yang baik dalam hal standarisasi, sentralisasi, dan koordinasi aktivitas. Namun dari hasil pengamatan, penulis masih menemukan kelemahan pengendalian dalam spesialisasi aktivitas.

c. Komite Audit

Kedatangan komite audit pada saat-saat tertentu atau minimal dua kali dalam setahun menandakan tetap terpeliharanya komunikasi dengan dewan komisaris dan auditor interal maupun eksternal, sehingga menunjang keefektivitasan lingkungan pengendalian.

d. Penetapan Wewenang dan Tanggung Jawab

Dengan adanya wewenang dan tanggung jawab yang jelas untuk setiap bagian, naka setiap bagian dapat melaksanakan tugasnya dengan baik dalam mencapai tujuan perusahaan.

e. Metode Pengendalian Manajemen

Metode pengendalian manajemen yang diterapkan oleh perusahaan sudah cukup mendukung terciptanya lingkungan pengendalian yang baik, mengingat jenis perusahaan farmasi dalam hal ini apotek terdapat barang dagangan tertentu yang hanya dapat dijual dijual berdasarkan resep dokter, tidak secara bebas pengedarannya maupun barang yang dibatasi jumlah persediaannya sehingga harus melampirkan sisa stok barang bersama SP.

2. Penilaian Resiko

a. Perubahan dalam Lingkungan Operasi Perusahaan

Perubahan secara struktural menunjukkan kecermatan dalam pengantisipasian persaingan sehingga dpat terus bersaing dalam unit bisnis farmsi dan mempercepat tercapainya tujuan perusahaan.

b. Karyawan Baru

Kriteria-kriteria tertentu yang ditetapkan dalam perekrutan karyawan merupakan kebijakan yang cukup baik agar karyawan tersebut tidak memerlukan waktu yang lama dalam penyesuaian dengan tugas yang akan dikerjakannya.

3. Informasi dan Komunikasi

Terpeliharanya komunikasi yang baik antara atasan dan bawahan, antara pihak perusahaan dengan pihak lain dalam pemberian informasi yang penting dapat segera 
didiskusikan untuk mendapatkan solusi yang terbaik mengenai kendala/masalah yang timbu sehingga penyelesaian terbaik pun dapat dicapai, bukan hanya kepentingan perusahaan, juga kepentingan pihak lain seperti konsumen.

4. Aktivitas Pengendalian

a. Pemisahan Tugas

Dalam melaksanakan kegiatan pengendalian, PT. Kimia Farma Apotek telah menerapkan pemisahan fungsi pengendalian dengan baik dimana fungsi perencanaan/pengadaan, pembayaran, pencatatan, dan penerimaan/penyimpanan/pengeluaran dilakukan oleh bagian terpisah.

5. Pemantauan

Proses pemantauan yang dilakukan oleh manajer bisnis apotek dibantu oleh auditor internal sudah cukup baik.

Tabel 1

Hasil Analisis Unsur-Unsur Pengendalian Internal

Pada PT. Kimia Farma Apotek

\begin{tabular}{|c|c|c|c|}
\hline Teori & Penerapan & Hasil Analisis & Skala Efektif \\
\hline \begin{tabular}{ll}
\multicolumn{1}{c}{ Lingkungan } \\
Pengendalian \\
1. & $\begin{array}{l}\text { Prubahan dalam } \\
\text { Lingkungan } \\
\text { Operasi Perusahaan }\end{array}$
\end{tabular} & \begin{tabular}{ll}
\multicolumn{1}{c}{ Lingkungan } \\
Pengendalian \\
1. & Dilakukan apabila \\
secara struktural \\
struktur tidak \\
relevan lagi dengan \\
keadaan \\
perusahaan.
\end{tabular} & $\begin{array}{l}\text { Lingkungan Pengendalian } \\
\text { 1. Baik adanya sehingga } \\
\text { dapat terus bersaing } \\
\text { dalam unit bisnis } \\
\text { farmasi. }\end{array}$ & 3 \\
\hline 2. Karyawan Baru & $\begin{array}{l}\text { 2. Ditetapkan kriteria } \\
\text { dalam perektrutan } \\
\text { karyawan, } \\
\text { pelaksanaan } \\
\text { program on the } \\
\text { traning. }\end{array}$ & $\begin{array}{l}\text { 2. Sudah baik untuk } \\
\text { mengurangi resiko } \\
\text { kesalaahan dalam } \\
\text { pelaksanaan pekerjaan. }\end{array}$ & 4 \\
\hline $\begin{array}{l}\text { 3. Perubahan Sistem } \\
\text { Informasi }\end{array}$ & $\begin{array}{l}\text { 3. Tidak terdapat } \\
\text { perubahan sistem } \\
\text { informasi. }\end{array}$ & $\begin{array}{l}\text { 3. Sebaiknya perubahan } \\
\text { dilakukan jika } \\
\text { diperlukan. }\end{array}$ & 2 \\
\hline $\begin{array}{l}\text { 4. Pertumbuhan yang } \\
\text { Pesat }\end{array}$ & $\begin{array}{ll}\text { 4. } & \text { Program } \\
\text { Pengembangan } \\
\text { Perusahaan yang } \\
\text { terus menerus. }\end{array}$ & $\begin{array}{l}\text { 4. Berdampak pada resiko } \\
\text { penambahan modal. }\end{array}$ & 2 \\
\hline 5. Teknologi Baru & $\begin{array}{l}\text { 5. Website baru, } \\
\text { pengusahaan atas } \\
\text { sistem online } \\
\text { persediaan dan } \\
\text { kartu member. }\end{array}$ & $\begin{array}{l}\text { 5. Menciptakan kedekatan } \\
\text { dengan pemegang } \\
\text { saham, dalam membantu } \\
\text { manajemen persediaan, } \\
\text { memacu kesetiaan } \\
\text { pelanggan. }\end{array}$ & 4 \\
\hline $\begin{array}{l}\text { 6. Lingkup Produk } \\
\text { atau Kegiatan Baru }\end{array}$ & $\begin{array}{l}\text { Fokus terhadap } \\
\text { produk farmasi } \\
\text { berbahan dasar }\end{array}$ & $\begin{array}{l}\text { 6. Baik adanya dalam } \\
\text { mengundang } \\
\text { ketertarikan konsumen, } \\
\text { karena kealamiannya }\end{array}$ & \\
\hline
\end{tabular}




\begin{tabular}{|c|c|c|c|}
\hline Teori & Penerapan & Hasil Analisis & Skala Efektif \\
\hline $\begin{array}{l}\text { 7. Restrukturasi } \\
\text { Perusahaan } \\
\\
\text { 8. Keputusan } \\
\text { Akuntansi }\end{array}$ & $\begin{array}{l}\text { herbal. } \\
\text { 7. Perubahan jabatan } \\
\text { dan penambahan } \\
\text { staf baru. } \\
\\
\text { 8. Penerapan prinsip } \\
\text { akuntansi masih } \\
\text { berdasarkan } \\
\text { standar akuntansi } \\
\text { yang berlaku } \\
\text { umum. }\end{array}$ & $\begin{array}{l}\text { dan lebih murah. } \\
\text { 7. Adanya semangat baru } \\
\text { namun juga dapat } \\
\text { menyebabkan } \\
\text { kesalahpahaman dalam } \\
\text { pemberian dan } \\
\text { penerimaan perintah. } \\
\text { 8. Baik adanya selama } \\
\text { meminimalkan resiko } \\
\text { kerugian dan } \\
\text { meningkatkan laba } \\
\text { perusahaan. }\end{array}$ & . \\
\hline
\end{tabular}

Sumber: Data Olahan

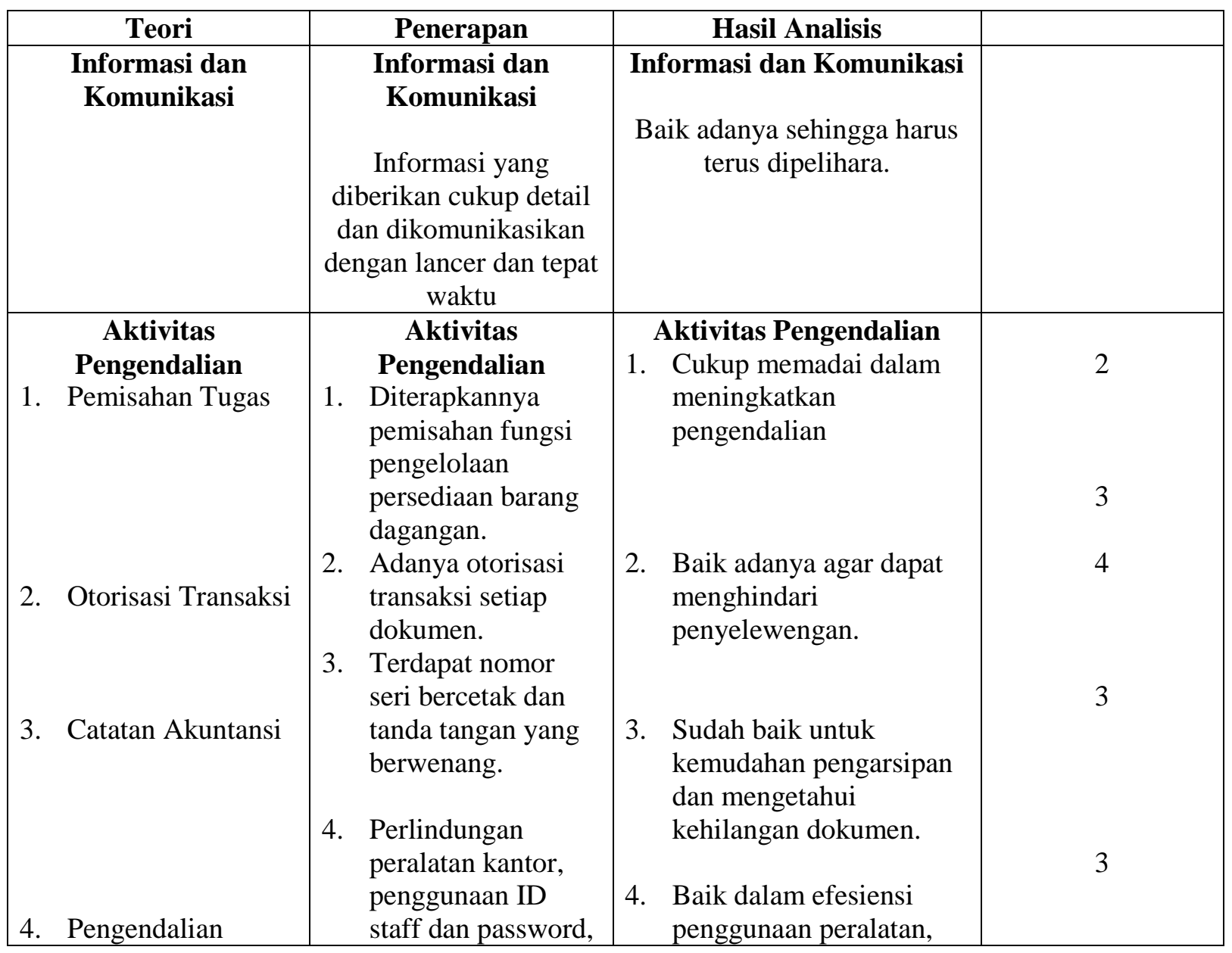




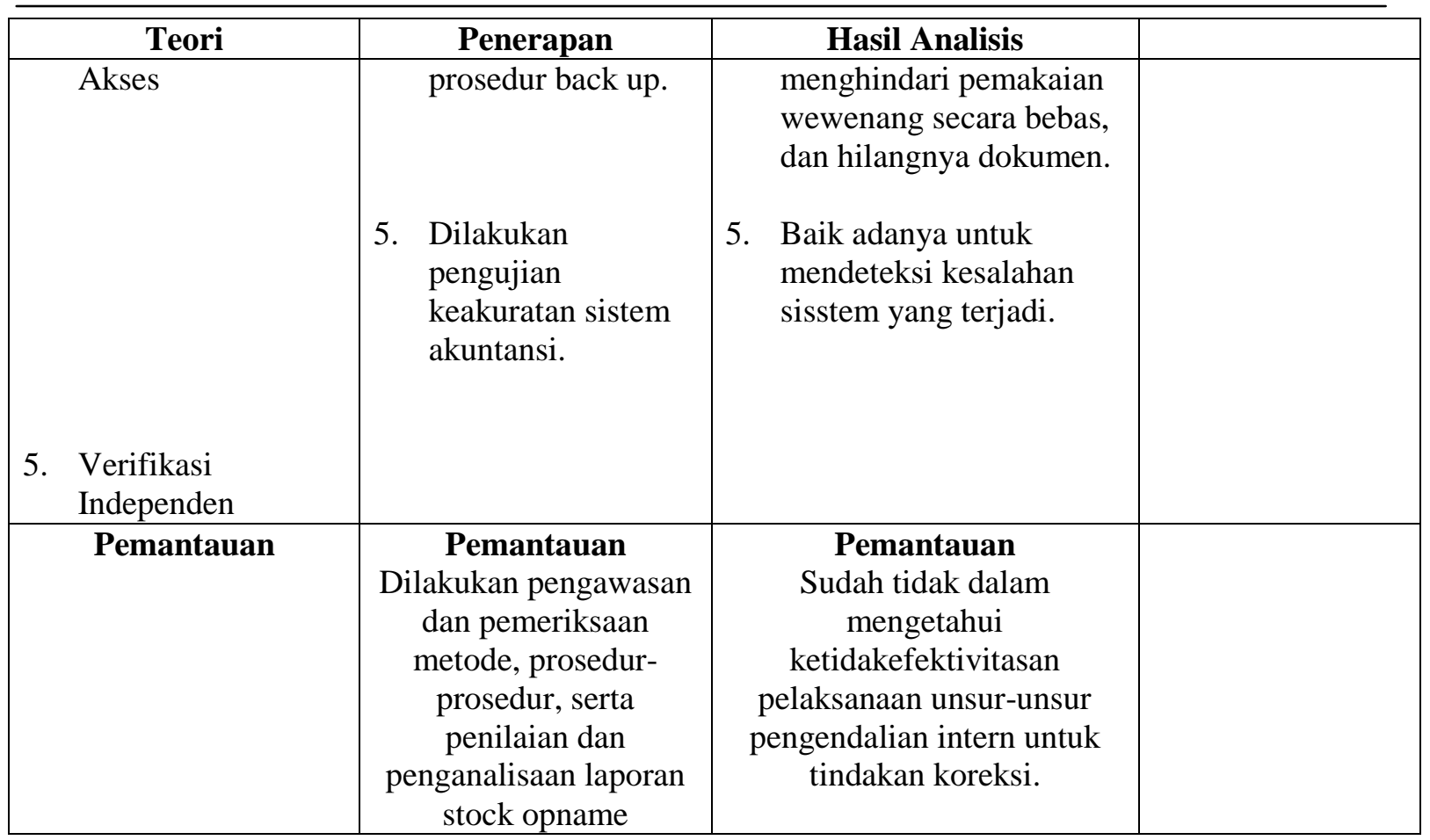

Sumber: Data Olahan

\section{KESIMPULAN DAN SARAN}

5.1 Kesimpulan

Pelaksanaan pengendalian internal persediaan barang dagangan yang diterapkan oleh

PT. Kimia Farma Apotek telah efektif. kesimpulan ini didukung oleh hal-hal berikut ini

1. Unsur-unsur pengendalian internal persediaan yang efektif.

a. Lingkungan pengendalian telah memadai dengan adanya falsafah manajemen, gaya operasi sentralisasi, struktur organisasi berbentuk lini dengan uraian tugas, wewenang dang tanggung jawab yang jelas, terdapat komite audit di pusat, berlakunya praktek dan kebijakan karyawan, pertimbangan pengaruh eksternal terhadap kompetitor dan peraturan pemerintah. Kelemahan yang ada yaitu fungsi auditor internal yang dirangkap oleh supervisor keuangan\&akuntansi dalam keseharian aktivitas perusahaan sehingga tidak independen, juga tidak adanya pemisahan fungsi antara penerimaan dan penyimpanan barang.

b. Penilaian resiko yang cukup memadai dengan dilakukannya perubahan lingkungan operasi, sistem informasi dan keputusan akuntansi jika diperlukan, terus mengikuti pertumbuhan yang pesat dengan adanya focus produk baru dan pengusahaan teknologi baru.

Adanya restrukturasi perusahaan dan prosedur perekrutan karyawan baru.

c. Informasi dan komunikasi telah memadai, dengan adanya komunikasi yang baik antara atasan dan bawahan, pihak perusahaan dengan pihak lain. Penyajian informasi yang cukup detail dan segera mungkin dikomunikasikan untuk tindak lanjut akan penyelesaian yang terbaik.

d. Aktivitas pengendalian telah memadai dengan adanya pemisahan tugas yang memiliki otorisasi transaksi atas wewenang masing-masing, didukung oleh format dokumen yang dibuat menggunakan komputer, memiliki nomor seri cetak dan tempat tanda tangan. Dilaksanakannya pengendalian akses dan verifikasi independen.

e. Pemantauan dilakukan langsung oleh manajer bisnis apotek mengenai pelaksanaan metode-metode dan prosedur-prosedur dalam perusahaan, juga oleh 
auditor intenal terhadap terpenuhinya unsur-unsur pengendalian internal dalam perusahaan. Khusus yang berhubungan dengan persediaaan barang dagangan, pemantauan dilakukan melalui penilaian dan penganalisisan laporan stock opname.

2. Pengendalian internal atas persediaan yang efektif

Adanya kegiatan perhitungan fisik, pembuatan prosedur-prosedur pengelolaan persediaan barang dagangan, penyimpanan persediaan yang baik, pembatasan akses persediaan, penggunaan sistem perpetual, pembelian persediaan dalam jumlah yang ekonomis, yang cukup banyak dan tidak terlalu banyak.

\subsection{Saran}

Sebaiknya kepada PT. Kimia Farma apotek yang bermanfaat dalam mengatasi kelemahan yang terdapat dalam sistem pengendalian intern atas persedian barang dagangan.

1. Sebaiknya perusahaan mempertimbangkan dalam menugaskan bagian atau menunjuk personel yang khusus menangani penerimaan barang sendiri yang terpisah dengan bagian yang melakukan fungsi penyimpanan barang. Begitu juga dalam hal pengelolaan kas, sebaiknya pemegang kas hanya melakukan fungsi penyimpanan kas tidak untuk penerimaan kas.

2. Sebaiknya perusahaan mempertimbangkan hal pembuatan fungsi audit internal di cabang yang berdiri sendiri agar proses audit dapat dilakukan secara teratur dan fungsi tersebut tidak dirangkap oleh supervisor Keuangan dan Akuntansi. Dengan adanya fungsi audit internal sendiri diharapkan kegiatan operasional cabang dapat terpantau lebih baik lagi karena sudah lebih independen dalam menilai keefektivitasan pelaksanaan unsur-unsur pengendalian intern persediaan barang dagangan yang telah ditetapkan oleh manajemen.

3. Kebijakan perusahaan dalam menentukan resiko persediaan barang dagangan dapat ditingkatkan dengan lebih tanggap terhadap perubahan teknologi dan informasi, perubahan peraturan pemerintah,serta penilaian resiko terhadap faktor kadaluarsa produk farmasi. Hal ini dilakukan untuk menjaga kredibilitas PT. Kimia Farma Apotek yang harus berpacu dengan tingkat persaingan yang semakin ketat di era globalisasi ini.

4. Perbaikan terhadap CCTV sebagai salah satu fasilitas dalam gudang sebaiknya segera dilakukan karena itu cukup membantu pengawasan untuk tindakan pencurian.

\section{DAFTAR PUSTAKA}

Aprilia, 2014.Penerapan Sistem Pengendalian Intern untuk Persediaan Barang Dangangan pada CV. Multimedia Persada Manado. Universitas Sam Ratulangi Manado Fakultas Ekonomi dan Bisnis.

Cyntia, 2015.Analisis Efektivitas Pengendalian Intern Persediaan Barang Dagang pada Grand Hardware Manado. Universitas Sam Ratulangi Manado Fakultas Ekonomi dan Bisnis. Committee of Sponsoring Organization of the Treadway Commission (COSO), 2013.

Hery, 2009, Akuntansi Intermedite Illustrasi Problem dan Solusi, Edisi 1, Grasindo, Jakarta. Jay M. Smith, K. Fred Skousen, Akuntansi Intermediate, Edisi Kesembilan, Jilid 1, Erlangga, Jakarta.

Libby. R. Patricia, Libby \& Daniel Short, 2008. Akuntansi Keuangan, Edisi Kelima. Andi, Yogyakarta.

Lining, 2008.Improving Inventory Management in Small Business, Jonkoping University.

McLeod dalam Susanto 2007, Sistem Informasi Akuntansi.

Mulyadi2010, Sistem Akuntansi, Edisi Ketiga, Salemba Empat, Jakarta. 
Nicolas, 2012.Improving Warehouse and Inventory Management (Operational Efficiency and Transport Safety).Jamk University Of Applied Science.

Nova, 2014. Evaluasi Pengendalian Intern untuk Siklus Persediaan Barang Dagangan pada SPBU Kolongan.Universitas Sam Ratulangi Manado Fakultas Ekonomi dan Bisnis.

Raven, 2016. Analisis Penyajian Laporan keuangan Berdasarkan SAK-ETAP pada Koperasi Karyawan Bank Sulut Go. Universitas Sam Ratulangi Manado Fakultas Ekonomi dan Bisnis.

Rosmeri Elsye., Suwanda Dadang., \& Muchidin Umuh,. 2016. Dasar-Dasar Akuntansi Akrual Pemerintah Daerah, Jatinangor; Ghalia Indonesia.

Siska, 2014. Analisis Sistem Pengendalian Persediaan Barang Dagang pada PT. Sungai Budi di Palembang.

Smith.Skousen, Nugrohowidjajanto, 1984, Akuntansi Intermediate, Edisi Kedelapan, Jilid 1, Erlangga, Jakarta. 